\title{
Utilizing buprenorphine-naloxone to treat illicit and prescription-opioid dependence
}

\author{
This article was published in the following Dove Press journal: \\ Neuropsychiatric Disease and Treatment \\ 7 April 2014 \\ Number of times this article has been viewed
}

\author{
Sofie Mauger ${ }^{1}$ \\ Ronald Fraser ${ }^{1,2}$ \\ Kathryn Gill ${ }^{1,2}$ \\ 'Department of Psychiatry, McGill \\ University, Montreal, QC, Canada; \\ ${ }^{2}$ Addictions Unit, McGill University \\ Health Centre, Montreal, QC, Canada
}

Objectives: To review current evidence on buprenorphine-naloxone (bup/nx) for the treatment of opioid-use disorders, with a focus on strategies for clinical management and office-based patient care.

Quality of evidence: Medline and the Cochrane Database of Systematic Reviews were searched. Consensus reports, guidelines published, and other authoritative sources were also included in this review. Apart from expert guidelines, data included in this review constitute level 1 evidence.

Findings: $\mathrm{Bup} / \mathrm{nx}$ is a partial $\mu$-opioid agonist combined with the opioid antagonist naloxone in a 4:1 ratio. It has a lower abuse potential, carries less stigma, and allows for more flexibility than methadone. Bup/nx is indicated for both inpatient and ambulatory medically assisted withdrawal (acute detoxification) and long-term substitution treatment (maintenance) of patients who have a mild-to-moderate physical dependence. A stepwise long-term substitution treatment with regular monitoring and follow-up assessment is usually preferred, as it has better outcomes in reducing illicit opioid use, minimizing concomitant risks such as human immunodeficiency virus and hepatitis $\mathrm{C}$ transmission, retaining patients in treatment and improving global functioning.

Conclusion: Bup/nx is safe and effective for opioid detoxification and substitution treatment. Its unique pharmaceutical properties make it particularly suitable for office-based maintenance treatment of opioid-use disorder.

Keywords: Zubsolv, Suboxone, methadone, opiate detoxification, opiate substitution, clinical management

\section{Introduction}

Dependence on opioids is a major health issue worldwide. The costs associated with opioid dependence are extensive, exacting an enormous toll in terms of health care, mental illness, quality of life, unemployment, and crime. Concomitant risks include the transmission of the human immunodeficiency virus (HIV), hepatitis B virus, hepatitis $\mathrm{C}$ virus (HCV), and tuberculosis, as well as a high incidence of death due to respiratory depression and overdose. ${ }^{1-6}$ It is well recognized that the abuse of prescription opioids is on the rise in North America as well as Australia and New Zealand. ${ }^{6-9}$ In numerous street-drug populations in both the US and Canada, prescription opioids have replaced heroin as the main opioid of choice. ${ }^{2,10}$ Moreover, US medical emergencies related to opioid misuse increased by $183 \%$ between 2004 and $2011 .^{11}$

Given the high medical and psychiatric comorbidities associated with opioid abuse, both primary care physicians and mental health specialists are regularly confronted with the sequelae of prescription and illicit opioid dependence. ${ }^{12,13}$ Pharmacological
Correspondence: Ronald Fraser Addictions Unit, McGill University Health Centre, 1547 Pine Avenue West, Montreal, QC H3G IB3, Canada $\mathrm{Tel}+\mathrm{I} 5 \mid 49341934$

Fax +I 5149348262

Email ronald.fraser@mcgill.ca 
substitution therapies, including buprenorphine and methadone, have been shown to be more effective than any other type of treatment for opioid dependence, particularly when used in combination with psychosocial interventions. ${ }^{14}$ Methadone, which is often administered through specialized licensed opioid-treatment programs, has been the standard of care for illicit opioid dependence for the past 40 years, particularly in the US. However, the lack of global access to specialized methadone clinics, strict regulations, long waiting lists, and stigma often discourage patients from enrolling in substitution treatment. ${ }^{15-17}$ In Europe, buprenorphine (Subutex) was introduced widely in primary care facilities as an alternative to methadone for the treatment of opioid dependence, with demonstrated success. ${ }^{18,19}$ Prescription opioid-dependent patients in particular may be amenable to treatment in primary care or office-based practice rather than specialized addiction-treatment centers. They appear to be younger and of higher socioeconomic status, with a lower prevalence of HCV infection, fewer years of opioid use, and fewer prior addiction-treatment episodes compared to patients receiving treatment for illicit opioid dependence. ${ }^{20}$

In the US, buprenorphine and buprenorphine-naloxone (bup/nx) were approved by the US Food and Drug Administration (FDA) in 2002, offering an office-based maintenance treatment for opioid dependence. ${ }^{21-23}$ Like methadone, buprenorphine and bup/nx substitution treatment have been shown to decrease hospital admissions, morbidity, and mortality. ${ }^{24-26}$ Moreover, buprenorphine is associated with lower risk of overdose and diversion, thereby offering more flexibility to both physicians and patients. ${ }^{12,27}$ The combination of buprenorphine with the opiate antagonist naloxone (bup/nx) demonstrates the same benefits as buprenorphine alone, with the added benefit of further reducing potential misuse.

Considering its safety profile, as well as its diminished abuse potential, bup/nx constitutes a promising alternative therapy for opioid dependence that could be used by general medical and mental health practitioners, thereby increasing access to substitution treatment. However, evidence is accumulating at a rapid pace, making it challenging for physicians unfamiliar with this topic to obtain the appropriate knowledge. In order to counteract barriers to the drug's clinical use, this article was designed as a comprehensive review of the literature surrounding the use of bup/nx in the treatment of illicit and prescription-opioid dependence.

\section{Quality of evidence}

A Cochrane Database of Systematic Reviews and Medline search on Ovid of all published articles identified with the keyword "buprenorphine" was conducted as of June 2013, limiting the search to human studies published in English. It yielded a total of 2,160 potential articles. Studies related to pain control were eliminated. Subsequently, all other abstracts were reviewed, and relevant studies with adequate methodology, including randomized controlled trials, metaanalyses, and systematic reviews, were selected and reviewed in depth. Consensus reports and guidelines published by the Center for Substance Abuse Treatment, the Royal Australian College of Physicians, the Centre for Addiction and Mental Health, the Community Care Behavioral Health Organization, the American Society of Addiction Medicine, and the World Health Organization were also included in this review. Apart from expert guidelines, data included in this review constitute level 1 evidence.

\section{Pharmacology/pharmacokinetics Buprenorphine}

Originally developed for pain treatment, buprenorphine is a semi-synthetic derivative of the opioid thebaine. Buprenorphine has a mixed agonist-antagonist action on opioid receptors: it acts as a partial agonist at the $\mu$-receptor and as an antagonist at the $\kappa$-receptor. ${ }^{28,29}$ As a partial agonist with low intrinsic activity, it produces milder and less euphoric and sedating opioid effects while still occupying opioid receptors, thus preventing withdrawal in dependent patients. ${ }^{30}$ There is also a "ceiling effect," in which the agonist properties increase linearly up to a maximum of 16-32 mg daily, followed by a plateau, in which further increases in dosage produce no pharmacological effects..$^{29,31}$ As a result, the intensity of the rewarding effects is milder than other full $\mu$-opioid agonists at higher doses, and the risk of abuse as well as respiratory depression is lower. ${ }^{30,32}$

Buprenorphine has a higher affinity for the $\mu$-receptor than other opioids, such as heroin, so it reduces the effects of full agonists and can in fact precipitate withdrawal symptoms in those actively using other opioids. ${ }^{33-35}$ This high affinity combined with a slow dissociation from the $\mu$-receptor also results in milder withdrawal symptoms upon discontinuation compared to methadone and other opioids. ${ }^{36-38}$

Sublingual buprenorphine has a long half-life (24-60 hours, mean 37 hours), and it is highly bound to plasma proteins $(96 \%)$. It has poor oral bioavailability, because it is inactivated by gastric acid and undergoes significant first-pass metabolism in the liver. It is metabolized by cytochrome P450 (CYP) 3A4 to various metabolites, including the active norbuprenorphine. ${ }^{28,32}$ Peak plasma concentrations are achieved in 90-150 minutes following 
administration, and the $\mu$-receptor blockade can last for 3-5 days due to the slow dissociation from the receptor, allowing for the possibility of alternate-day dosing. ${ }^{39}$

\section{Buprenorphine-naloxone (Suboxone)}

Suboxone $^{\circledR}$ (Reckitt Benckiser Pharmaceuticals Inc., Richmond, VA, USA) is formulated as a combination of buprenorphine with the opiate antagonist naloxone in a 4:1 ratio. Naloxone binds tightly to the opioid receptor without producing a euphoric effect, thereby blocking or reversing the psychoactive effects of partial- or full-opioid agonists. ${ }^{40}$ Naloxone has poor bioavailability in the sublingual form; therefore, it does not alter buprenorphine's properties when the medication is taken as prescribed..$^{28,41}$ If bup/nx is injected, however, sufficient naloxone is absorbed to precipitate acute withdrawal in opiate-dependent users, thus discouraging further abuse via the intravenous route of administration. ${ }^{40,42,43}$

\section{Dosing and formulation}

$\mathrm{Bup} / \mathrm{nx}$ is available sublingually in tablet (Zubsolv ${ }^{\circledR}[$ Orexo $\mathrm{AB}$ with AAIPharma, Wilmington, NC, USA] and generic) or film formulation (Suboxone). The Suboxone film is offered in bup $/ \mathrm{nx}$ doses of $2 / 0.5 \mathrm{mg}, 4 / 1 \mathrm{mg}, 8 / 2 \mathrm{mg}$, and $12 / 3 \mathrm{mg}$, while the generic tablet only exists in doses of $2 / 0.5 \mathrm{mg}$ and $8 / 2 \mathrm{mg}$. Zubsolv, a new sublingual tablet with higher bioavailability, received FDA approval in July 2013, and is distributed in $1.4 / 0.36 \mathrm{mg}$ and 5.7/1.4 dosages. ${ }^{44}$ All formulations and dosage strengths can be dispensed in the US for take-home use by prescription. Bup/nx is formulated as a combination of buprenorphine with the opiate antagonist naloxone in a 4:1 ratio. Bup/nx doses will be stated in terms of mg buprenorphine in the text below, as well as in the figures.

The target dose for maintenance therapy is usually $16 \mathrm{mg}$ buprenorphine per day, although most recent guidelines favor an individualized approach with no specific dose or range recommendations. In both inpatient and outpatient settings, the therapeutic goal is to find the lowest dose to eliminate illicit opioid use, reduce withdrawal symptoms, and improve treatment retention. ${ }^{34}$ The final maintenance dose is likely to be in the range of 4-24 $\mathrm{mg}$ buprenorphine per day. ${ }^{45}$ Due to the ceiling effect, there is no added benefit of increasing the daily dose above $32 \mathrm{mg}$ per day. ${ }^{29,31}$

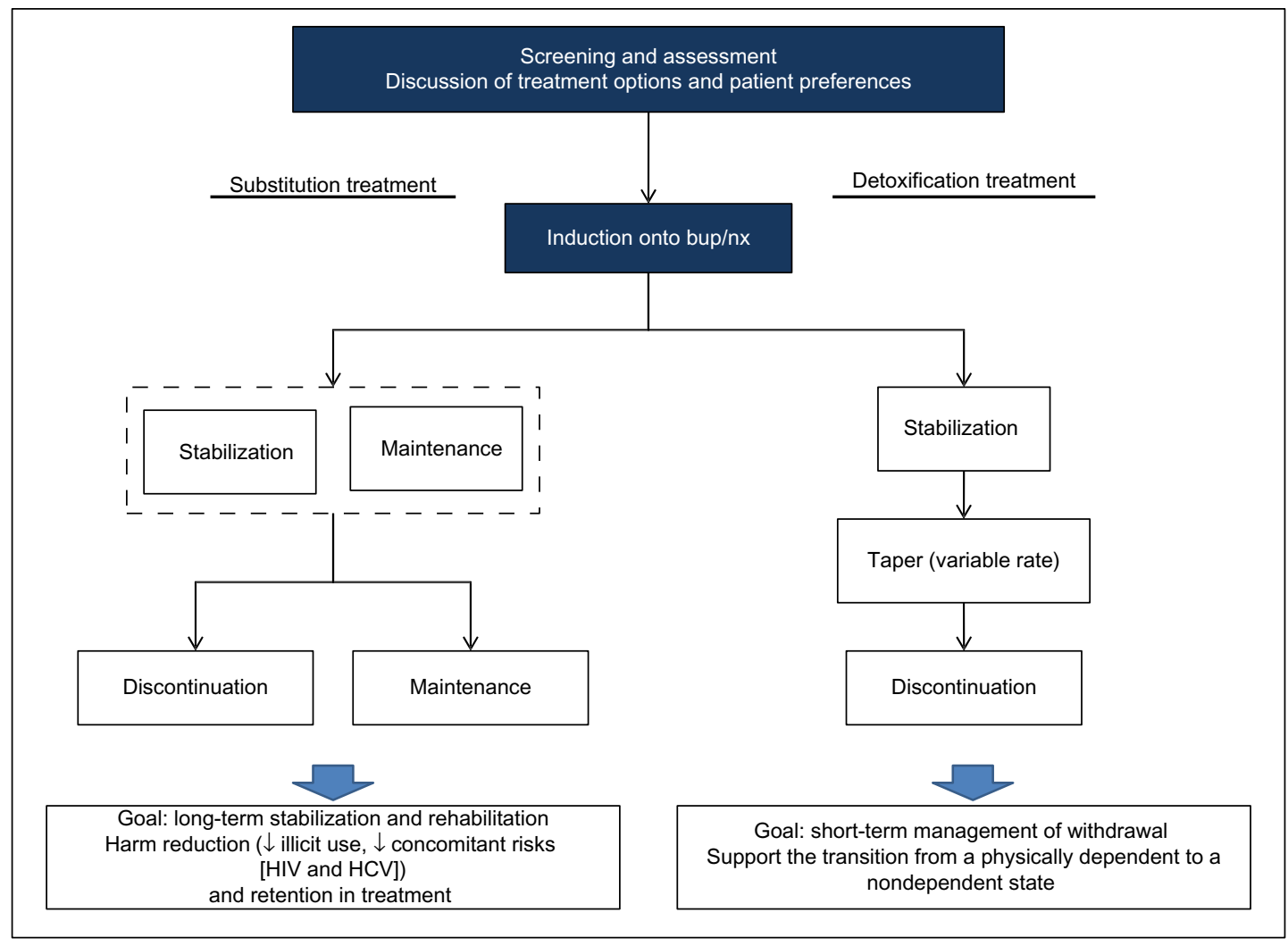

Figure I Clinical management: opioid substitution versus acute detoxification.

Abbreviations: Bup/nx, buprenorphine-naloxone; HIV, human immunodeficiency virus; HCV, hepatitis C virus. 


\section{Strategy for clinical management}

There are two general approaches to the medical treatment of opioid addiction: medically supervised detoxification and opioid-substitution treatment (Figure 1). Bup/nx is indicated for both acute detoxification and long-term substitution among patients who have a mild-to-moderate physical dependence on opioids. ${ }^{45}$ All treatment options can be carried out in an inpatient or ambulatory setting. ${ }^{34}$ In medical detoxification, bup/nx is used as replacement therapy to help support the transition from a physically dependent to a nondependent state. Although it can sometimes lead to total abstinence, it has a low success rate and relapse rates are high. ${ }^{46-48}$ Younger patients who are only dependent on oral opioids, with a short history of dependence, a good support system, and no significant psychiatric comorbidities, have a better prognosis with this approach. ${ }^{33}$

Among chronic intravenous drug users, opioid substitution is usually the preferred treatment approach. Substitution or maintenance treatment refers to the long-term use of a longacting opioid (eg, bup/nx) with graduated take-home doses to manage opioid dependence. The goal is to reduce illicit opioid use and injection behavior, minimize concomitant risks such as HIV and HCV infection, and retain patients in treatment. ${ }^{34,49,50}$ Long-term substitution treatment has better outcomes than medically supervised detoxification, and should be considered within the context of a harm-reduction approach. ${ }^{51}$
As shown in Figure 1, treatment is initiated with a thorough screening and assessment of opioid dependence, including a discussion of available treatment options and patient preferences. This is followed by an induction phase, in which patients are transferred from their opioid of abuse to bup/nx. Details related to assessment, induction, stabilization, maintenance, and detoxification are provided in the following sections.

\section{Screening and assessment}

The initial screening and assessment should include comprehensive medical, psychiatric, and psychosocial evaluations in order to confirm a diagnosis of opioid dependence. ${ }^{45}$ The decision to initiate either medical detoxification or long-term substitution treatment should be guided by the severity of dependence, prior treatment history, and the patient's preferences. Assessment of addiction severity is essential, as it will guide buprenorphine dosing and treatment needs, including potential risk of diversion. Consideration should be given to the time since the last opioid dose, the type of opioid used (long- versus short-acting), and the degree of physical dependence. ${ }^{52}$ Due to opioid dependence, comorbidities and potential side effects of bup/nx, a pregnancy test, baseline liver enzymes, and HCV, Hepatitis B virus (HBV), and HIV testing are recommended prior to induction. ${ }^{33}$

Table I Induction onto bup/nx for short-, long-, and ultralong-acting opioids

\begin{tabular}{|c|c|c|c|}
\hline & $\begin{array}{l}\text { Short-acting } \\
\text { (eg, heroin, oxycodone) }\end{array}$ & $\begin{array}{l}\text { Long-acting } \\
\left.\text { (eg, morphine, OxyContin }{ }^{\circledR}\right)\end{array}$ & $\begin{array}{l}\text { Ultralong-acting } \\
\text { (eg, methadone) }\end{array}$ \\
\hline $\begin{array}{l}\text { Stage I: Early withdrawal } \\
\text { - Fear of withdrawal, anxiety, craving }\end{array}$ & 4-6 hours & $8-12$ hours & $12-24$ hours \\
\hline $\begin{array}{l}\text { Stage II: Mid-withdrawal } \\
\text { - Insomnia, restlessness, anxiety, } \\
\text { yawning, stomach cramps, lacrimation, } \\
\text { rhinorrhea, diaphoresis, mydriasis }\end{array}$ & $8-12$ hours & I 2-24 hours & $36-72$ hours \\
\hline $\begin{array}{l}\text { Stage III: Late withdrawal } \\
\text { - Diarrhea, vomiting, fever, chills, } \\
\text { piloerection, muscle spasms, tremor, } \\
\text { tachycardia, and hypertension }\end{array}$ & 24-72 hours & $48-72$ hours & $72-96$ hours \\
\hline Induction onto bup/nx & $\begin{array}{l}\text { I. Switch to bup/nx } \\
\text { I2-24 hours from last } \\
\text { dose when in moderate } \\
\text { withdrawal (COWS }>12 \text { ) } \\
\text { 2. The goal is to reach a target } \\
\text { dose of } 12-16 \mathrm{mg} \\
\text { buprenorphine during } \\
\text { the first week }\end{array}$ & $\begin{array}{l}\text { I. Switch to bup/nx } \\
\text { I8-36 hours from last } \\
\text { dose, when in moderate } \\
\text { withdrawal (COWS }>\text { I2) } \\
\text { OR } \\
\text { I. Switch to equivalent } \\
\text { dose of short-acting opiate } \\
\text { 2. Maintain dose } \times 3 \text { days, } \\
\text { 3. Switch to bup/nx as per } \\
\text { short-acting opiates }\end{array}$ & $\begin{array}{l}\text { I. Taper methadone dose } \\
\text { to } 30 \mathrm{mg} / \text { day } \\
\text { 2. Maintain } 30 \mathrm{mg} / \text { day } \times 5-7 \text { days } \\
\text { 3. Switch to bup/nx }>24 \text { hours } \\
\text { after last dose, when in } \\
\text { moderate withdrawal } \\
\text { (COWS }>12 \text { ) }\end{array}$ \\
\hline
\end{tabular}

Note: Sources of data: Kosten and O'Connor, ${ }^{55}$ Dijkstra et al, ${ }^{56}$ and Farrell. ${ }^{57}$

Abbreviations: Bup/nx, buprenorphine-naloxone; COWS, Clinical Opioid Withdrawal Scale. 


\section{Induction phase}

Bup/nx induction entails titration over 1-3 days until a comfortable level is reached. Patients can be started on bup/nx 6-24 hours after the last opiate dose, when they develop objective signs of spontaneous withdrawal. ${ }^{28,45,53,54}$ As shown in Table 1, cravings usually begin 4-6 hours after the last dose of a short-acting opioid, and the withdrawal pattern is delayed with ultralong-acting opioids, such as methadone. The main features of opioid withdrawal are nausea, vomiting, diaphoresis, yawning, fatigue, aches and pain, diarrhea, mydriasis, and piloerection. ${ }^{57}$ Subjective symptoms are much greater than objective signs, and weak withdrawal discomfort is usually experienced after 36-72 hours and decreases thereafter. ${ }^{57,58}$ In theory (and practice), administration of a partial opioid agonist (bup/nx) exerts the least antagonistic effect when the patient is experiencing mild-to-moderate withdrawal symptoms. ${ }^{32}$ If the patient is not in sufficient withdrawal when the first dose of bup/nx is administered, buprenorphine will displace the full-opioid agonist (eg, heroin) and intensify rather than relieve withdrawal symptoms (precipitated withdrawal). If precipitated withdrawal occurs, patients will experience intensified withdrawal symptoms after the first induction dose. ${ }^{32-35}$ Validated assessment tools, such as the Clinical Opioid Withdrawal Scale (scores >12) and the Clinical Institute Narcotic Assessment can be used to ensure that patients are in moderate withdrawal prior to bup/nx induction. ${ }^{59}$

The initial dose is $2-4 \mathrm{mg}$ buprenorphine, which is increased based on clinical symptoms up to a total first-day

Table 2 Approximate opioid equivalencies compared with $10 \mathrm{mg}$ of IV morphine

\begin{tabular}{lll}
\hline Generic name & $\begin{array}{l}\text { Potency ratio } \\
\text { (in IV morphine } \\
\text { equivalent) }\end{array}$ & $\begin{array}{l}\text { Equivalent } \\
\text { doses (mg) }\end{array}$ \\
\hline Fentanyl & I00-200 & \\
Hydromorphone IV & 5 & $0.05-0.1$ \\
Heroin & $\mathrm{I}-2$ & 1.5 \\
Hydromorphone PO & 1.3 & $5-10$ \\
Morphine IV & $\mathrm{I}$ & 7.5 \\
Methadone PO & 0.5 & 10 \\
Oxycodone PO & 0.5 & 20 \\
Morphine PO & 0.5 & 20 \\
Meperidine IM & 0.13 & $20-30$ \\
Codeine PO & 0.05 & 75 \\
Meperidine PO & 0.03 & 200 \\
\hline Notes: & 300 \\
\hline
\end{tabular}

Notes: aEquivalencies are approximate, and should be used with clinical judgment clinicians must be particularly careful when the total equivalent opioid dose is more than $100 \mathrm{mg}$ of methadone. Data source: Ducharme et al. ${ }^{61}$ Table originally published in Canadian Family Physician and reprinted with permission. Copyright (c) 2012. Abbreviations: IM, intramuscular; IV, intravenous; PO, per os. dose of $8 \mathrm{mg} .{ }^{28}$ The goal is to reach the target dose of $12-16$ mg buprenorphine during the first week. ${ }^{34} \mathrm{~A}$ recent retrospective chart-review study $(n=40)$ suggested that more rapid buprenorphine initiation up to $16 \mathrm{mg}$ on the first day was well tolerated ${ }^{60}$ As indicated in Table 1, prior to induction onto bup/nx, it is possible to substitute long-acting opioids with an equivalent dose of a short-acting medication. Table 2 provides an approximate equivalency among the various opioids and routes of administration. ${ }^{61}$ However, clinicians must be aware that equivalency tables have not been developed for chronic (tolerant) opioid-dependent populations, and the information in Table 2 must therefore be employed with clinical judgment. Extrapolating from Mattick et al, 6-12 mg buprenorphine would correspond roughly to 35-60 mg of methadone. ${ }^{62}$

Induction is one of the most critical phases of bup/nx treatment. A detailed chart indicating the procedures and decision points during the first day of bup/nx induction is provided in Figure 2. An association has been established between difficult induction (strong withdrawal symptoms and cravings) and poorer treatment retention and outcome. ${ }^{63-65}$ Evidence also suggests that increasing the induction dose more rapidly is associated with better treatment outcome. ${ }^{66}$ Therefore, patients should be observed regularly during the induction period to exclude precipitated withdrawal, signs of overmedication (eg, sedation) or unwanted side effects, and to confirm the effectiveness of the dose at suppressing withdrawal symptoms. ${ }^{34,58}$ Current guidelines recommend direct observation of initial dosage of bup/nx for 2-4 hours, with a series of subsequent visits for dose adjustments. ${ }^{34,45,67,68}$ Observed induction can, however, present significant challenges to many office-based practitioners, and as an alternative, "home" or unobserved induction has been proposed. Evidence supporting this practice is accumulating, but further research is still needed to confirm the feasibility and safety of this innovative treatment approach. ${ }^{13,68-71}$ To favor compliance, initial prescription of bup/nx can be written daily in order to provide supervised medication dispensing. ${ }^{72}$

Note that a bup/nx combination can be used for induction treatment in most patients. However, pregnant women and patients who are on ultralong-acting opioids (eg, methadone) should be induced using buprenorphine monotherapy ${ }^{45,73}$ instead of bup/nx. The transition from methadone to buprenorphine is gaining popularity, due to a more flexible outpatient setting, safer side-effect profile, and lower potential for misuse and abuse. ${ }^{74-77}$ However, concerns about the possibility of inducing significant withdrawal during the 


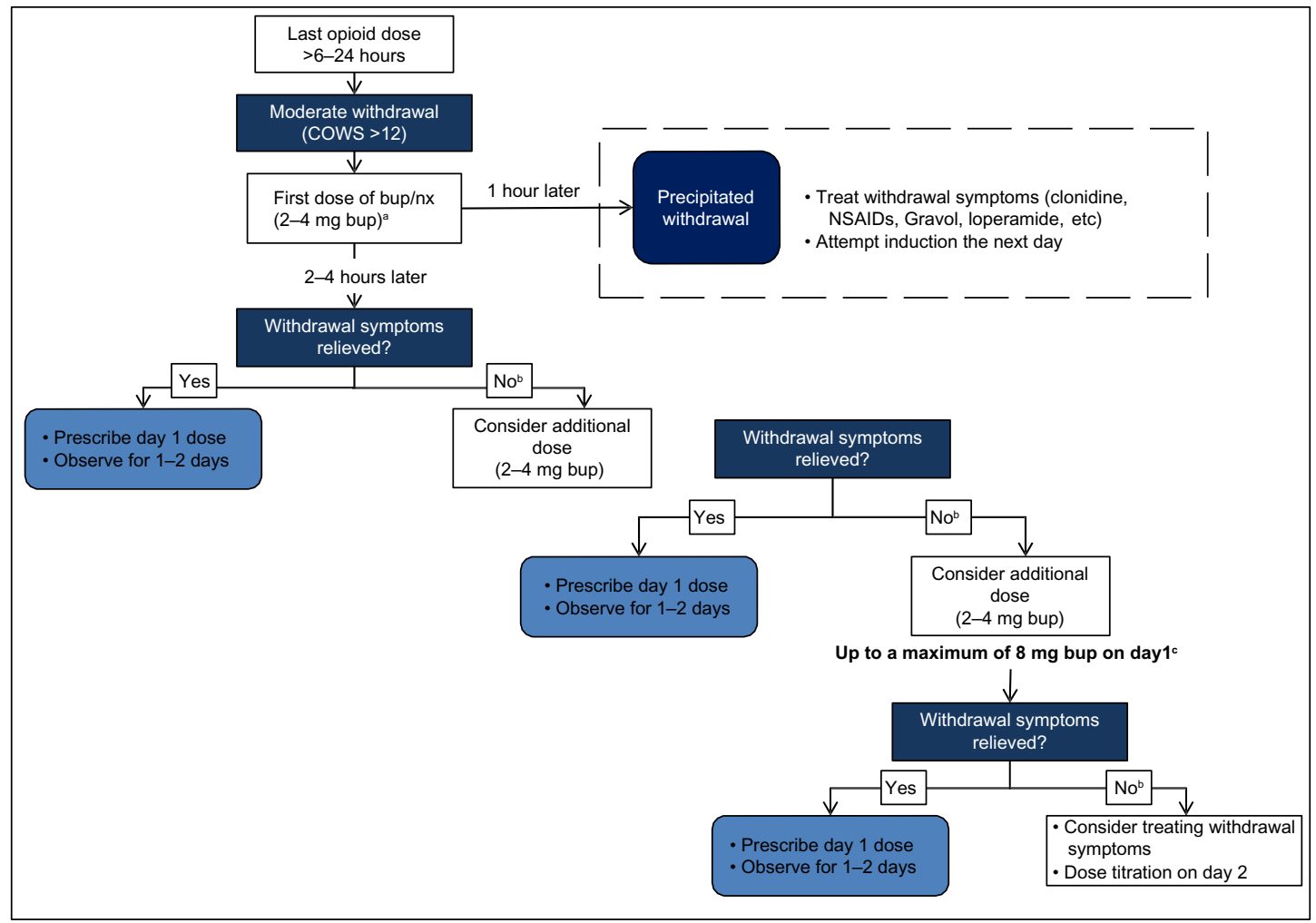

Figure 2 Bup/nx induction (day I).

Notes: ${ }^{a}$ Use higher dose (4 mg bup) in patients in severe withdrawal; ${ }^{b}$ no improvement in withdrawal symptoms or persisting signs of mild-to-moderate withdrawal (COWS >4); ' 'Gunderson et al ${ }^{60}$ suggests going up to $16 \mathrm{mg}$ on the first day. Data sources: Center of Addiction and Mental Health, ${ }^{33}$ Substance Abuse and Mental Health Services Administration, ${ }^{34}$ Community Care Behavioral Health Organization, ${ }^{45}$ Tompkins et al, ${ }^{59}$ Gunderson et al, ${ }^{60}$ and Kraus et al. ${ }^{73}$

Abbreviations: Bup/nx, buprenorphine-naloxone; COWS, Clinical Opioid Withdrawal Scale; NSAIDs, nonsteroidal anti-inflammatory drugs; bup, buprenorphine.

induction procedure limit the practice. ${ }^{78,79}$ Prior to the transition to buprenorphine, methadone dose should be gradually tapered to 30-40 mg per day and maintained at this dose or lower for at least 5-7 days. The patient should then discontinue methadone for $48-72$ hours prior to receiving the first dose of buprenorphine. ${ }^{45}$

\section{Stabilization and maintenance}

Stabilization begins when the patient is no longer having withdrawal symptoms or cravings and there are minimal side effects from bup/nx. The goal is to find the minimum dose that eliminates withdrawal symptoms, prevents other opioid use, decreases cravings, and improves psychosocial functioning (the maintenance dose) ${ }^{80,81}$ As each patient must be dosed individually, medication adjustment can take up to 1-2 months (7-14 days in acute detoxification), with slow increments/decrements every 5-7 days achieved through weekly contact with the patient during early stabilization. The Suboxone manufacturer recommends that dosing be observed for the first 2 months, even though this treatment protocol is not always possible in clinical practice. Relapse should be ruled out when a stable patient's dosing requirements change suddenly. ${ }^{45,54}$
During the maintenance phase, moderate-to-high doses (8-16 mg buprenorphine) have been shown to be significantly more efficacious than low doses (1-4 mg buprenorphine). ${ }^{62,82,83}$ Although the maximum recommended dose by the Suboxone manufacturer is $24 \mathrm{mg}$, doses of up to $32 \mathrm{mg}$ have been used in some trials.$^{84} \mathrm{~A}$ recent observational retrospective chart-review study showed that using a flexible dosing schedule with the option of titrating the dose up to $32 \mathrm{mg}$ offered better treatment outcomes, especially for patients who did not respond to lower doses. ${ }^{85}$

The optimum duration of maintenance is unclear, but it may involve long-term or even lifetime medication use. ${ }^{86}$ Patients who were induced with buprenorphine for the transition from methadone to bup/nx should be switched to bup/nx for maintenance once transition is complete. ${ }^{34}$ An alternate-day dosing schedule of bup/nx is possible, and this may be preferred or better tolerated by some patients. ${ }^{34,45}$ The weekly dose can then be divided by the number of days of dosing (eg, double dose for alternate days). Routine urine toxicology screens can be utilized to assess bup/nx compliance and detect the use of other prescribed, undisclosed, or illicit substances (eg, alcohol, benzodiazepines, morphine, oxycodone, etc), although evidence for the cost-effectiveness of urine testing is weak. ${ }^{72}$ On-site dispensing 
or observed taking of bup/nx is indicated until the patient has a negative urine screen or is compliant with treatment. ${ }^{45}$

\section{Discontinuation (detoxification)}

In medically supervised withdrawal, reaching an opioid-free state is the ultimate goal of treatment, and discontinuation can also be considered for patients on long-term maintenance treatment. However, tapering off or cessation of bup/nx should only be considered for patients who are motivated to discontinue, have a stable income and housing arrangements, and have adequate psychosocial support. ${ }^{34}$ Dose-reduction protocols range from 3 days (short), 10-14 days (moderate), to months (long). ${ }^{34,45,73}$ Initial studies yielded conflicting results about the optimal duration of the taper. ${ }^{87-89}$ A recent large randomized trial demonstrated that after a month of stabilization on Suboxone treatment, a 7-day taper was equivalent to a 28-day taper in terms of the number of opioid-free urine samples. ${ }^{90}$ Conversely, another comparative study suggested that a 30-day taper enhanced participation in longer-term treatment compared with a 5-day taper. ${ }^{91}$ Recent guidelines suggest a gradual bup/nx discontinuation with a taper of no more than 2 mg every 5-7 days. ${ }^{33,34,73}$ It is important to assess

Table 3 Symptomatic treatment of opioid withdrawal

\begin{tabular}{|c|c|c|}
\hline $\begin{array}{l}\text { Withdrawal } \\
\text { symptoms }\end{array}$ & $\begin{array}{l}\text { Somatic } \\
\text { treatment }\end{array}$ & Dosing \\
\hline $\begin{array}{l}\text { Nausea and } \\
\text { vomiting }\end{array}$ & $\begin{array}{l}\text { Dimenhydrinate } \\
(\text { Gravol } \\
\text { Prochlorperazine } \\
\left(\text { Stemeti }{ }^{\circledR}\right)\end{array}$ & $\begin{array}{l}\text { 50-100 mg PO/IM q4h prn } \\
5-10 \mathrm{mg} \text { PO q4h prn }\end{array}$ \\
\hline Diarrhea & $\begin{array}{l}\text { Loperamide } \\
\text { (Imodium }^{\circledast} \text { ) }\end{array}$ & $\begin{array}{l}4 \mathrm{mg} P O \text { for diarrhea, } \\
\text { then } 2 \mathrm{mg} \mathrm{PO} \text { prn } \\
(\max : 16 \mathrm{mg} / 24 \mathrm{hr} \text { ) }\end{array}$ \\
\hline Myalgia & $\begin{array}{l}\text { Acetaminophen } \\
\left(\text { Tylenol }^{\circledR}\right) \\
\text { Naproxen } \\
\left(\text { Naprosyn }^{\circledR}\right)\end{array}$ & $\begin{array}{l}325-650 \mathrm{mg} \text { PO q4h prn } \\
\text { (max: } 4,000 \mathrm{~g} / 24 \mathrm{hr} \text { ) } \\
500 \mathrm{mg} \text { PO bid } \times 4 \text { days, } \\
\text { then prn }\end{array}$ \\
\hline $\begin{array}{l}\text { Anxiety, } \\
\text { dysphoria, } \\
\text { lacrimation, } \\
\text { rhinorrhea }\end{array}$ & $\begin{array}{l}\text { Hydroxyzine } \\
\left(\text { Atarax }^{\circledR}\right)\end{array}$ & $25-50 \mathrm{mg} P O$ tid prn \\
\hline Insomnia & $\begin{array}{l}\text { Trazodone } \\
\left(\text { Trazorel }^{\circledR}\right)\end{array}$ & $\begin{array}{l}50-100 \mathrm{mg} \text { PO qhs } \times \\
4 \text { days, then prn }\end{array}$ \\
\hline $\begin{array}{l}\downarrow \text { Sympathetic } \\
\text { drive (tachycardia, } \\
\text { hypertension), } \\
\text { diaphoresis, } \\
\text { restlessness }\end{array}$ & $\begin{array}{l}\text { Clonidine } \\
\left(\text { Nexiclon }^{\circledR}\right)^{\text {a }}\end{array}$ & $\begin{array}{l}0.1 \mathrm{mg} \text { PO qid } \times 4 \text { days, then } \\
0.05 \mathrm{mg} \text { PO qid } \times 2 \text { days, then } \\
0.025 \mathrm{mg} \text { PO qid, then stop }\end{array}$ \\
\hline
\end{tabular}

Notes: anonitor blood pressure prior to each dose, as clonidine may cause hypotension; bif $<91 \mathrm{~kg}(200 \mathrm{lb}$ ) (doses need to be higher if $>9 \mathrm{l} \mathrm{kg}$ ). Data source: Kosten and O'Connor ${ }^{55}$ and Kleber et al. ${ }^{92}$

Abbreviations: PO, per os; IM, intramuscular; q4h, quaque 4 hora (every 4 hours) prn, pro re nata (as needed); bid, bis in die (twice a day); tid, ter in die (three times a day); qhs, quaque hora somni (every night at bedtime); qid, quater in die (four times a day); max, maximum; hr, hours. the patient regularly during the discontinuation process. If withdrawal symptoms emerge as the dose is decreased, the taper can be temporarily suspended. ${ }^{34}$ Medications commonly used to alleviate withdrawal symptoms are presented in Table 3. Following completion of the taper, naltrexone, an opioid-receptor antagonist that blocks the euphoric effects of opioids, can also be used to minimize the risk of relapse to opioid abuse. ${ }^{92}$

\section{Integrated multidisciplinary approach}

A purely pharmacological approach to medication-assisted recovery is rarely sufficient. ${ }^{93}$ The goals of psychosocial interventions (counseling, self-help groups, and rehabilitation programs) are to engage patients in the process of change and retain them in treatment long enough to improve global functioning and quality of life. Contingencymanagement techniques that use motivational incentives to condition or influence behaviors (eg, receiving a "voucher" with monetary value for negative urine-toxicology screening), have been found to help in initiating and maintaining abstinence among addiction patients. ${ }^{94}$ These resources are available in structured treatment programs as well as in the community.

The outcome of bup/nx treatment is best when combined with psychosocial counseling, prevention education, and recovery-support services. ${ }^{67,95-97}$ The best evidence to support the value of a multidisciplinary approach in the treatment of opioid addiction comes from a Cochrane review by Amato et al. ${ }^{14}$ This meta-analysis included eleven studies and evaluated five different psychosocial interventions and two pharmaceutical treatments (buprenorphine and methadone). The combination of pharmacological and psychosocial treatment was significantly superior in reducing dropout rates (relative risk [RR] 0.71), decreasing relapses or use of full agonist opioids (RR 0.82), and improving treatment compliance in terms of follow-up visits (RR 0.48). Currently, there are no data supporting a specific type of psychosocial approach. Despite limited evidence, most clinicians feel that bup/nx treatment should be accompanied by voluntary psychosocial counseling, participation in formal treatment programs and/or attendance at mutual aid groups, such as Narcotics Anonymous. ${ }^{14,86}$

\section{Patient-focused perspectives}

$\mathrm{Bup} / \mathrm{nx}$ is usually well tolerated. It is a safe pharmacological treatment, with expected side effects of sedation, constipation, headache, nausea/vomiting, and dizziness. It has a lower risk of respiratory depression than full agonists, and 
is associated with less QTc prolongation than methadone..$^{98,99}$ Liver-function tests should be periodically monitored. ${ }^{28,100}$

Many of the randomized trials on buprenorphine did not examine tolerability. In a 4-week randomized double-blind phase of a 52-week study comparing the efficacy of bup/ nx with placebo, the most frequently reported adverse events were headache, withdrawal symptoms, pain, nausea, insomnia, and sweating. No serious treatment-related adverse events have been reported, except increases in hepatic alanine aminotransferase and aspartate aminotransferase. ${ }^{101}$ These are all expected side effects of bup/nx.

Bup/nx is sometimes favored because it carries less stigma than methadone. Patients also appear to prefer bup/nx due to its more flexible administration schedule, which enables office-based treatment and allows lower clinic-attendance requirements for medication dispensing and carry-outs. ${ }^{102}$ The main barrier to using bup/nx is its high cost, especially when compared to methadone. ${ }^{24,62,103}$ Moreover, buprenorphine programs tailored for marginalized populations with unstable lifestyles and greater risk of comorbidities and infectious disease transmission are currently limited. ${ }^{73}$

\section{Special populations}

\section{Hepatitis and liver disease}

Buprenorphine is contraindicated in patients suffering from severe liver disease only, with liver-function tests three to five times above the upper limit of normal. ${ }^{73}$ It can be used safely in patients with hepatitis whose liver-function tests are below that range.

\section{Concomitant drug dependence}

The combination of bup/nx with sedative-hypnotics (eg, benzodiazepines, alcohol) has been associated with increased mortality, mainly due to respiratory depression. ${ }^{28,100}$ Sedative-hypnotic-dependent patients should be advised to reduce or discontinue their use prior to induction, and urinetoxicology testing should be performed regularly to assess concomitant use. ${ }^{45}$ Active use of alcohol, benzodiazepines, and barbiturates is therefore a relative contraindication to buprenorphine outpatient treatment, and medically supervised withdrawal is suggested. ${ }^{104-106}$

\section{Pregnancy and children}

$\mathrm{Bup} / \mathrm{nx}$ is contraindicated for pregnant women, as naloxone has not been approved for use in pregnancy. Buprenorphine monotherapy, like methadone, which has been the standard of care in obstetric care since the 1970s, has been shown to reduce illicit opiate use, enhance compliance, and improve neonatal outcomes, such as birth weight. ${ }^{107-110}$ Recently, the Maternal Opioid Treatment: Human Experimental Research (MOTHER) study confirmed these conclusions and suggested the superiority of buprenorphine in terms of fetal outcomes, with less frequent and severe neonatal abstinence syndrome compared to methadone. ${ }^{109,110}$

The use of buprenorphine in women who are breastfeeding remains controversial. Both buprenorphine and its main metabolite (norbuprenorphine) appear at low concentrations in breast milk, levels that are unlikely to contribute to buprenorphine dependence in the infant. Due to limited data, the risks and benefits of buprenorphine exposure should be weighed before initiating or continuing substitution treatment among breastfeeding women. ${ }^{110,111}$

Intoxication with bup/nx in children is relatively safe. ${ }^{84}$ In a retrospective study, the main clinical effects were drowsiness or lethargy (55\%), vomiting (21\%), miosis (21\%), respiratory depression $(7 \%)$, agitation or irritability $(5 \%)$, pallor (3\%), and coma ( $2 \%)$, with no reports of death. None of these severe effects occurred in children who ingested less than $4 \mathrm{mg}$ buprenorphine. ${ }^{112}$ Children should be referred to emergency for all ingestions of over $2 \mathrm{mg}$ buprenorphine or any type of ingestion in patients under 2 years old. ${ }^{33}$

\section{Adolescents and youth}

Few studies have evaluated buprenorphine and bup/nx in the treatment of adolescents with opioid dependence. There is good evidence suggesting that youth are at higher risk of mortality and morbidity from opioid-use disorders (overdose, HIV and hepatitis transmission, concurrent disorders, suicide, and death). ${ }^{113-116}$ The risk-benefit ratio of bup/nx treatment should therefore be carefully evaluated prior to buprenorphine initiation. If substitution treatment with opioid agonists is considered, bup/nx may be preferred over methadone. Bup/ $\mathrm{nx}$ prescribing in adolescents and young adults follows the same steps and dosages as in adults. ${ }^{33,113}$

\section{HIV patients}

Bup/nx is associated with enhanced HIV outcomes, including increased antiretroviral therapy (ART) initiation, compliance and $\mathrm{CD}^{+}{ }^{+}$count. ${ }^{117}$ However, it should be used with caution in patients with HIV on ART due to the potential for drug interactions. In theory, several nonnucleoside reversetranscriptase inhibitors and protease inhibitors are CYP3A4 inducers (efavirenz, nevirapine, nelfinavir, lopinavir/ritonavir) or inhibitors (delavirdine, ritonavir, atazanavir/ritonavir), and thereby the combination has the potential to alter the metabolism of buprenorphine, ART, or both. Some studies 
suggest that dose adjustments may be required, but no cases of opioid toxicity have been reported. ${ }^{118}$

\section{Conclusion}

Opioid addiction is a serious public health problem that results in significant individual and social costs, including increased disability, criminal activity, death from overdose, and risk of infectious and blood-borne disease transmission. ${ }^{1-4,6,34} \mathrm{Bup} / \mathrm{nx}$, a partial-opioid agonist with unique pharmacological properties, is the only office-based maintenance treatment offered for opioid-use disorders. It is an attractive option for opioid-substitution therapy because of its favorable side-effect profile, flexible dosing schedules, and low diversion and abuse potential. It has demonstrated efficacy in reducing opiate cravings, ameliorating withdrawal discomfort, and increasing periods of abstinence from illicit drug use. In most cases, treatment is required for long periods or even throughout life. ${ }^{86,92}$ Rather than being considered a treatment failure, long-term treatment, which is common to many chronic medical conditions, should be envisaged as a cost-effective way to prolong longevity and improve quality of life.

Although bup/nx has shown multiple benefits, the cost of the medication hinders its widespread use, mainly for marginalized populations and street-heroin users. Members of these populations are at greater risk of comorbidities and infectious disease transmission, and thus it is crucial to increase access to efficacious treatments.

Physicians who wish to prescribe bup/nx in the US and Canada must complete a training program. More exhaustive continuing medical education programs are available for physicians with less experience in treating opioid dependence.

\section{Disclosure}

The authors report no conflicts of interest in this work.

\section{References}

1. Degenhardt L, Bucello C, Calabria B, et al. What data are available on the extent of illicit drug use and dependence globally? Results of four systematic reviews. Drug Alcohol Depend. 2011;117:85-101.

2. Fischer B, Argento E. Prescription opioid related misuse, harms, diversion and interventions in Canada: a review. Pain Physician. 2012;5:ES191-ES203.

3. Friedland G. Infectious disease comorbidities adversely affecting substance users with HIV: hepatitis C and tuberculosis. J Acquir Immune Defic Syndr. 2010;55:S37-S42.

4. Stockman JK, Strathdee SA. HIV among people who use drugs: a global perspective of populations at risk. J Acquir Immune Defic Syndr. 2010;55:S17-S22.

5. Substance Abuse and Mental Health Services Administration (SAMHSA). State Estimates of Substance Use and Mental Disorders from the 2008-2009 National Surveys on Drug Use and Health. Rockville, MD: SAMHSA; 2011.
6. United Nations Office on Drugs and Crime (UNODC). World Drug Report 2013. Vienna: UN; 2013. Available from: http://www.unodc.org/ unodc/secured/wdr/wdr2013/World_Drug_Report_2013.pdf.Accessed November 18, 2013

7. European Monitoring Center on Drugs and Drug Abuse (EMCDDA). Annual Report 2011: The State of the Drugs Problem in Europe. Luxembourg: EMCDDA; 2011. Available from: http://www.emcdda. europa.eu/publications/annual-report/2011. Accessed November 18, 2013.

8. Holmes D. Prescription drug addiction: the treatment challenge. Lancet. 2012;379:17-18.

9. Royal Australasian College of Physicians (RACP). Prescription Opioid Policy: Improving Management of Chronic Nonmalignant Pain and Prevention of Problems Associated with Prescription Opioid Use. Sydney: RACP; 2009. Available from: https://www.racp.edu.au/ index.cfm?objectid=EA87198D-CA47-AB21-072D9B2F26FD4AA3. Accessed November 18, 2013.

10. Sigmon $\mathrm{S}$. Characterizing the emerging population of prescription opioid abusers. Am J Addict. 2006;15:208-212.

11. Substance Abuse and Mental Health Services Administration. Drug Abuse Warning Network, 2011: national estimates of drug-related emergency department visits. 2013. Available from: http://www. Samhsa.gov/data/2k13/DAWN2k11ED/DAWN2k11ED.htm. Accessed November 18, 2013

12. Gwin Mitchell S, Kelly SM, Brown BS, et al. Uses of diverted methadone and buprenorphine by opioid-addicted individuals in Baltimore, Maryland. Am J Addict. 2009;18:346-355.

13. Sohler NL, Li X, Kunins HV, et al. Home- versus office-based buprenorphine induction for opioid-dependent patients. J Subst Abuse Treat. 2010;38:153-159.

14. Amato L, Minozzi S, Davoli M, Vecchi S. Psychosocial and pharmacological treatments versus pharmacological treatments for opioid detoxification. Cochrane Database Syst Rev. 2011;9: CD005031.

15. Friedman SR, Tempalski B, Cooper H, et al. Estimating numbers of injecting drug users in metropolitan areas for structural analyses of community vulnerability and for assessing relative degrees of service provision for injecting drug users. J Urban Health. 2004;81: $377-400$.

16. Peterson JA, Schwartz RP, Mitchell SG, et al. Why don't out-oftreatment individuals enter methadone treatment programs? Int J Drug Policy. 2010;21:36-42.

17. Popova S, Rehm J, Fischer B. An overview of illegal opioid use and health services utilization in Canada. Public Health. 2006;120:320-328.

18. Auriacombe M, Fatseas M, Dubernet J, Daulouede JP, Tignol J. French field experience with buprenorphine. Am J Addict. 2004;13:S17-S28.

19. Fatseas M,Auriacombe M. Why buprenorphine is so successful in treating opiate addiction in France. Curr Psychiatry Rep. 2007;9:358-364.

20. Moore B, Fiellin DA, Barry DT, et al. Primary care office-based buprenorphine treatment: comparison of heroin and prescription opioid dependent patients. J Gen Intern Med. 2007;22:527-530.

21. Fiellin DA. The first three years of buprenorphine in the United States: experience to date and future directions. J Addict Med. 2007;1: 62-67.

22. Knudsen HJ, Abraham AJ, Johnson JA, Roman PM. Buprenorphine adoption in the National Drug Abuse Treatment Clinical Trials Network. J Subst Abuse Treat. 2009;37:307-312.

23. Parran TV, Adelman CA, Merkin B, et al. Long-term outcomes of office-based buprenorphine/naloxone maintenance therapy. Drug Alcohol Depend. 2010;106:56-60.

24. Bell J, Trinh L, Butler B, Randall D, Rubin G. Comparing retention in treatment and mortality in people after initial entry to methadone and buprenorphine treatment. Addiction. 2009;104:1193-1200.

25. Jones ES, Moore BA, Sindelar JL, O'Connor PG, Schottenfeld RS, Fiellin DA. Cost analysis of clinic and office-based treatment of opioid dependence: results with methadone and buprenorphine in clinically stable patients. Drug Alcohol Depend. 2009;99:132-140. 
26. Nielsen S, Dietze P, Cantwell K, Lee N, Taylor D. Methadone and buprenorphine related ambulance attendances: a populationbased indicator of adverse events. J Subst Abuse Treat. 2008;35: 457-461.

27. Smith MY, Bailey JE, Woody GE, Kleber HD. Abuse of buprenorphine in the United States: 2003-2005. Journal of Addictive Diseases 2007;26:107-111.

28. Virani AS, Bezchlibnyk-Butler KZ, Jeffries JJ, Procyshyn RM. Clinical Handbook of Psychotropic Drugs. 19th ed. Bern: Hogrefe and Huber; 2012.

29. Mello NK, Mendelson J. Behavioral pharmacology of buprenorphine. Drug Alcohol Depend. 1985;14:283-303.

30. Lutfy K, Cowan A. Buprenorphine: a unique drug with complex pharmacology. Curr Neuropharmacol. 2004;2:395-402.

31. Walsh S, Preston K, Stitzer M, Cone E, Bigelow G. Clinical pharmacology of buprenorphine: ceiling effects at high doses. Clin Pharmacol Ther. 1994;55:569-580.

32. Strain EC, Preston K, Liebson I, Bigelow G. Buprenorphine effects in methadone-maintained volunteers: effect at two hours after methadone. J Pharmacol Exp Ther. 1995;272:628-638.

33. Centre for Addiction and Mental Health. Buprenorphine/Naloxone for Opioid Dependence: Clinical Practice Guideline. Toronto: CAMH; 2012. Available from: http://knowledgex.camh.net/primary_care/ guidelines_materials/Documents/buprenorphine_naloxone_gdlns2012. pdf. Accessed November 18, 2013.

34. Substance Abuse and Mental Health Services Administration. Clinical Guidelines for the Use of Buprenorphine in the Treatment of Opioid Addiction: A Treatment Improvement Protocol (TIP) 40. Rockville, MD: SAMHSA; 2004. Available from: http://buprenorphine.samhsa. gov/Bup_Guidelines.pdf. Accessed November 18, 2013.

35. Wesson DR. Buprenorphine in the treatment of opiate dependence: its pharmacology and social context of use in the US. J Psychoactive Drugs. 2004;Suppl 2:119-128.

36. Amass L, Ling W, Freese TE, et al. Bringing buprenorphine-naloxone detoxification to community treatment providers: the NIDA clinical trials network field experience. Am J Addict. 2004;13 Supp1 1: S42-S66.

37. Caldiero R, Parran T, Adelman C, Piche B. Inpatient initiation of buprenorphine maintenance vs detoxification: can retention of opioiddependent patients in outpatient counseling be improved? Am J Addict. 2006;15:1-7.

38. White J, Bell J, Saunders J, et al. Open-label dose-finding trial of buprenorphine implants (Probuphine) for treatment of heroin dependence. Drug Alcohol Depend. 2009;103:37-43.

39. Schuh K, Walsh S, Stitzer M. Onset, magnitude and duration of opioid blockade produced by buprenorphine and naltrexone in humans. Psychopharmacology. 1999;145:162-174.

40. Ling W, Jacobs P, Hillhouse M, et al. From research to the real world: buprenorphine in the decade of the Clinical Trials Network. J Subst Abuse Treat. 2010;38 Suppl 1:S53-S60.

41. Chiang CN, Hawks RL. Pharmacokinetics of the combination tablet of buprenorphine and naloxone. Drug Alcohol Depend. 2003; 70 Suppl 2:S39-S47.

42. Bigelow GE, Preston K, Liebson I. Abuse liability assessment of buprenorphine-naloxone combinations. NIDA Res Monogr. 1987;76: 145-149.

43. Preston KL, Bigelow G, Liebson I. Buprenorphine and naloxone alone and in combination in opioid-dependent humans. Psychopharmacology. 1988;94:484-490.

44. US Food and Drug Administration, Drugs@FDA: FDA-approved drug products. Available from: http:/www.accessdata.fda.gov/scripts/cder/ drugsatfda/index.cfm. Accessed November 18, 2013.

45. Community Care Behavioral Health Organization. Supporting recovery from opioid addiction: community care best practice guidelines for buprenorphine and Suboxone. 2013. Available from: http://www.ct.gov/ dmhas/lib/dmhas/publications/Community_Care_BP_Guidelines_for_ Buprenorphine_and_Suboxone.pdf. Accessed November 18, 2013.
46. Broers B, Giner F, Dumont P, Mino A. Inpatient opiate detoxification in Geneva: follow-up at 1 and 6 months. Drug Alcohol Depend. 2000;58:85-92.

47. Gossop M. Clonidine and the treatment of the opiate withdrawal syndrome. Drug Alcohol Depend. 1988;21:253-259.

48. Vaillant GE. What can long-term follow-up teach us about relapse and prevention of relapse in addiction? Br J Addict. 1988;83: 1147-1157.

49. Cornish R, Macleod J, Strang J, Vickerman P, Hickman M. Risk of death during and after opiate substitution treatment in primary care: prospective observational study in UK General Practice Research Database. BMJ. 2010;341:c5475.

50. Kimber J, Copeland L, Hickman M, et al. Survival and cessation in injecting drug users: prospective observational study of outcomes and effect of opiate substitution treatment. BMJ. 2010;341:c3172.

51. Dole VP, Nyswander ME. Heroin addiction - a metabolic disease. Arch Intern Med. 1967;120:19-24.

52. Johnson RE, Strain EC, Amass L. Buprenorphine: how to use it right. Drug Alcohol Depend. 2003;70:S59-S77.

53. Fiellin D, Kleber H, Trumble-Hejduk J, McLellan A, Kosten T. Consensus statement on office-based treatment of opioid dependence using buprenorphine. J Subst Abuse Treat. 2004;27:153-159.

54. Schering-Plough Canada. Suboxone Product Monograph. Kirkland, QC: Schering-Plough Canada; 2007.

55. Kosten TR, O'Connor PG. Management of drug and alcohol withdrawal. N Engl J Med. 2003;348:1786-1795.

56. Dijkstra BA, Krabbe PF, De Jong CA, van der Staak CP. Prediction of withdrawal symptoms during opioid detoxification. J Opioid Manag. 2008;4:311-319.

57. Farrell M. Opiate withdrawal. Addiction. 1994;89:1471-1475.

58. Kleber H. Detoxification from narcotics. In: Lowinson JH, Ruiz P, editors. Substance Abuse. Baltimore: Williams \& Wilkins; 1981.

59. Tompkins DA, Bigelow GE, Harrison JA, Johnson RE, Fudala PJ, Strain EC. Concurrent validation of the Clinical Opiate Withdrawal Scale (COWS) and single-item indices against the Clinical Institute Narcotic Assessment (CINA) opioid withdrawal instruments. Drug Alcohol Depend. 2009;105:154-159.

60. Gunderson EW, Levin FR, Rombone MM, Vosburg SK, Kleber HD. Improving temporal efficiency of outpatient buprenorphine induction. Am J Addict. 2011;20:397-404.

61. Ducharme S, Fraser R, Gill K. Update on the clinical use of buprenorphine in opioid-related disorders. Can Family Physician. 2012;58:37-41.

62. Mattick R, Kimber J, Davoli M. Buprenorphine maintenance versus placebo or methadone maintenance for opioid dependence. Cochrane Database Syst Rev. 2008;2:CD002207.

63. Nielsen S, Hillhouse M, Thomas C, Hasson A, Ling W. A comparison of buprenorphine taper outcomes between prescription opioid and heroin users. J Addict Med. 2013;7:33-38.

64. Soyka M, Zingg C, Koller G, Kuefner H. Retention rate and substance use in methadone and buprenorphine maintenance therapy and predictors of outcome: results from a randomized study. Int $J$ Neuropsychopharmacol. 2008;11:641-653.

65. Whitley SD, Sohler NL, Kunins HV, et al. Factors associated with complicated buprenorphine inductions. J Subst Abuse Treat. 2010;39:51-57.

66. Doran CM. Buprenorphine, buprenorphine/naloxone and methadone maintenance: a cost-effectiveness analysis. Expert Rev Pharmacoecon Outcomes Res. 2005;5:583-591.

67. Bonhomme J, Shim RS, Gooden R, Tyus D, Rust G. Opioid addiction and abuse in primary care practice: a comparison of methadone and buprenorphine as treatment options. J Natl Med Assoc. 2012;104: 342-350.

68. Lee JD, Grossman E, DiRocco D, Gourevitch MN. Home buprenorphine/naloxone induction in primary care. J Gen Intern Med. 2009;24: 226-232. 
69. Walley AY, Alperen JK, Cheng DM, et al. Office-based management of opioid dependence with buprenorphine: clinical practices and barriers. J Gen Intern Med. 2008;23(9):1393-1398.

70. Mintzer IL, Eisenberg M, Terra M, MacVane C, Himmelstein DU, Woolhandler S. Treating opioid addiction with buprenorphinenaloxone in community-based primary care settings. Ann Fam Med. 2007;5(2):146-150.

71. Gunderson EW, Wang XQ, Fiellin DA, Bryan B, Levin FR. Unobserved versus observed office buprenorphine/naloxone induction: a pilot randomized clinical trial. Addict Behav. 2010;35:537-540.

72. Farrell M, Wodak A, Gowing L. Maintenance drugs to treat opioid dependence. BMJ. 2012;344:e2823.

73. Kraus ML, Alford DP, Kotz MM, et al. Statement of the American Society of Addiction Medicine Consensus Panel on the use of buprenorphine in office-based treatment of opioid addiction. J Addict Med. 2011;5:254-263.

74. Ehret GB, Desmeules JA, Broers B. Methadone-associated long QT syndrome: improving pharmacotherapy for dependence on illegal opioids and lessons learned for pharmacology. Expert Opin Drug Saf. 2007;6:289-303.

75. Fishman MJ, Wu LT, Woody GE. Buprenorphine for prescription opioid addiction in a patient with depression and alcohol dependence. Am J Psychiatry. 2011;168:675-679.

76. Martell BA, Arnsten JH, Krantz MJ, Gourevitch MN. Impact of methadone treatment on cardiac repolarization and conduction in opioid users. Am J Cardiol. 2005;95:915-918.

77. Whitley SD, Kunins HV, Arnsten JH, Gourevitch MN. Colocating buprenorphine with methadone maintenance and outpatient chemical dependency services. J Subst Abuse Treat. 2007;33:85-90.

78. Manelli P, Peindl KS, Lee T, Bhatia KS, Wu LT. Buprenorphinemediated transition from opioid agonist to antagonist treatment: state of the art and new perspectives. Curr Drug Abuse Rev. 2012;5: $52-63$.

79. Knudsen HK, Ducharme LJ, Roman PM. Early adoption of buprenorphine in substance abuse treatment centers: data from the private and public sectors. J Subst Abuse Treat. 2006;30:363-373.

80. Baxter LE. Clinical Guidance on Methadone Induction and Stabilization. Chevy Chase (MD): American Society of Addiction Medicine; 2009.

81. Joseph H, Stancliff S, Lagrod J. Methadone maintenance treatment (MMT): a review of historical and clinical issues [review]. Mt Sinai J Med. 2000;67:347-364.

82. Ling W, Charuvastra C, Collins J, et al. Buprenorphine maintenance treatment of opiate dependence: a multicenter randomized clinical trial. Addiction. 1998;93:475-486.

83. Ahmadi J. Methadone versus buprenorphine maintenance for the treatment of heroin-dependent outpatients. J Subst Abuse Treat. 2003;24:217-220.

84. Kakko J, Grönbladh L, Svanborg K, et al. A stepped care strategy using buprenorphine and methadone versus conventional methadone maintenance in heroin dependence: a randomized controlled trial. Am J Psychiatry. 2007;164:797-803.

85. Fareed A, Vayalapalli S, Casarella J, Dexler K. Treatment outcome for flexible dosing buprenorphine maintenance treatment. Am J Drug Alcohol Abuse. 2012;38:155-160.

86. World Health Organization. Guidelines for the Psychosocially Assisted Pharmalogical Treatment of Opioid Dependence. Geneva: WHO; 2009. Available from: http:/www.who.int/substance_abuse/publications/ opioid_dependence_guidelines.pdf. Accessed January 30, 2014.

87. Wang R, Young L. Double-blind controlled detoxification from buprenorphine. NIDA Res Monogr. 1996;162:114.

88. Pycha C, Resnick R, Galanter M. Buprenorphine: rapid and slow dosereduction for heroin detoxification. NIDA Res Monogr. 1994;141:453.

89. Amass L, Bickel W, Higgins S, Hughes J. A preliminary investigation of outcome following gradual or rapid buprenorphine detoxification. J Addict Dis. 1994;13:33-45.
90. Ling W, Hillhouse M, Dornier C, et al. Buprenorphine tapering schedule and illicit opioid use. Addiction. 2009;104:256-265.

91. Katz EC, Schwartz RP, King S, et al. Brief vs extended buprenorphine detoxification in a community treatment program: engagement and short term outcomes. Am J Drug Alcohol Abuse. 2009;35:63-67.

92. Kleber HD, Weiss RD, Anton RF, et al. Practice guidelines for the treatment of patients with substance use disorders, second edition. Arlington (VA): American Psychiatric Association (APA); August 2006. http://psychiatryonline.org/pdfaccess.ashx?ResourceID $=243188 \&$ PDFSource=6. Accessed November 18, 2013.

93. Dutra L, Stathopoulou G, Basden SL, Leyro TM, Powers MB, Otto MW. A meta-analytic review of psychosocial interventions for substance use disorders. Am J Psychiatry. 2008;165:179-187.

94. Pendergast M, Podus D, Finney J, Greenwell L, Roll J. Contingency management for treatment of substance use disorders: a meta-analysis. Addiction. 2010;101:1546-1560.

95. Campbell BK, Fuller BE, Lee ES. Facilitating outpatient treatment entry following detoxification. Psychology of Addictive Behaviours. 2009;23(2):260-270.

96. Fiellin DA, Pantalon M, Chawarski M, et al. Counselling plus buprenorphine-naloxone maintenance therapy for opioid dependence. N Engl J Med. 2006;355:365-374.

97. Weiss RD, Potter JS, Provost SE, et al. A multi-site, two-phase, Prescription Opioid Addiction Treatment Study (POATS): Rationale, design, and methodology. Contemp Clin Trials. 2010;31: 189-199.

98. Wedam EF, Bigelow G, Johnson R, Nuzzo P, Haigney M. QTinterval effects of methadone, levomethadyl, and buprenorphine in a randomized trial. Arch Intern Med. 2007;167:2469-2475.

99. Ancherson K, Clausen T, Gossop M, Hansteen V, Waal H. Prevalence and clinical relevance of corrected QT interval prolongation during methadone and buprenorphine treatment: a mortality assessment study. Addiction. 2009;104:993-999.

100. Lange WR, Fudala P, Dax E, Johnson R. Safety and side-effects of buprenorphine in the clinical management of heroin addiction. Drug Alcohol Depend. 1990;26:19-28.

101. Fudala PJ, Bridge TP, Herbert S, et al. Office-based treatment of opiate addiction with a sublingual-tablet formulation of buprenorphine and naloxone. N Engl J Med. 2003;349:949-958.

102. Orman JS, Keating GM. Buprenorphine/naloxone: a review of its use in the treatment of opioid dependence. Drugs. 2009;69:577-607.

103. Mattick RP, Breen C, Kimber J, Davoli M. Methadone maintenance therapy versus no opioid replacement for opioid dependence. Cochrane Database Syst Rev. 2009;3:CD002209.

104. Fischer G, Ortner R, Rohrmeister K, et al. Methadone versus buprenorphine in pregnant addicts: a double-blind, double-dummy comparison study. Addiction. 2006;101:275-281.

105. Lavie E, Fatseas M, Denis C, Auriacombe M. Benzodiazepine use among opiate-dependent subjects in buprenorphine maintenance treatment: correlates of use, abuse and dependence. Drug Alcohol Depend. 2009;99:338-344.

106. House of Delegates of the Federation of State Medical Boards. Model Policy on DATA 2000 and Treatment of Opioid Addiction in Medical Offices. United States: Federation of State Medical Boards; April 2013. Available from: http://www.fsmb.org/pdf/2013_ model_policy_treatment_opioid_addiction.pdf. Accessed January 2014.

107. Kaltenbach K, Berghella V, Finnegan L. Opioid dependence during pregnancy: effects and management. Obstet Gynecol Clin North Am. 1998;25:139-151.

108. Fajemirokun-Odudeyi O, Sinha C, Tutty S, et al. Pregnancy outcome in women who use opiates. Eur J Obstet Gynecol Reprod Biol. 2006;126:170-175.

109. Jones HE, Kaltenbach K, Heil SH, et al. Neonatal abstinence syndrome after methadone or buprenorphine exposure. $N$ Engl J Med. 2010;363:2320-2331. 
110. Jones HE, Fischer G, Heil SH, et al. Maternal Opioid Treatment: Human Experimental Research (MOTHER) - approach, issues, and lessons learned. Addiction. 2012;107 Suppl 1:28-35.

111. Academy of Breastfeeding Medicine Protocol Committee, Jansson LM. ABM Clinical Protocol \#21: Guidelines for Breastfeeding and the Drug-Dependent Woman. Breastfeed Med. 2009;4:225-228.

112. Hayes BD, Klein-Schwartz W, Doyon S. Toxicity of buprenorphine overdoses in children. Pediatrics. 2008;121:e782-e786.

113. Bell J, Mutch C. Treatment retention in adolescent patients treated with methadone or buprenorphine for opioid dependence: a file review. Drug Alcohol Rev. 2006;25:167-171.

114. Woody G, Poole SA, Subramaniam G, et al. Extended vs short-term buprenorphine-naloxone for treatment of opioid-addicted youth: a randomized trial. JAMA. 2008;300:2003-2011.
115. Fiellin DA. Treatment of adolescent opioid dependence: no quick fix. JAMA. 2008;300:2057-2059.

116. Levy S, Vaughan BL, Angulo M, Knight JR. Buprenorphine replacement therapy for adolescents with opioid dependence: early experience from a children's hospital-based outpatient treatment program. J Adolesc Health. 2007;40:477-488.

117. Altice FL, Bruce RD, Lucas GM, et al. HIV treatment outcomes among HIV-infected, opioid-dependent patients receiving buprenorphine/naloxone treatment within HIV clinical care settings: results from a multisite study. J Acquir Immune Defic Syndr. 2011;56 Suppl 1: S22-S32.

118. McCance-Katz EF, Sullivan LS, Nallani S. Drug interactions of clinical importance between the opioids, methadone and buprenorphine, and frequently prescribed medications: a review. Am J Addict. 2009;19:4-16.

\section{Publish your work in this journal}

Neuropsychiatric Disease and Treatment is an international, peerreviewed journal of clinical therapeutics and pharmacology focusing on concise rapid reporting of clinical or pre-clinical studies on a range of neuropsychiatric and neurological disorders. This journal is indexed on PubMed Central, the 'PsycINFO' database and CAS.
The manuscript management system is completely online and includes a very quick and fair peer-review system, which is all easy to use. Visit http://www.dovepress.com/testimonials.php to read real quotes from published authors.

Submit your manuscript here: http://www.dovepress.com/neuropsychiatric-disease-and-treatment-journal 